\title{
Dietary fat intakes of school-going Irish adolescents aged 12-17 years
}

\author{
M. P. O'Connor ${ }^{1}$, N. M. O’Brien ${ }^{1}$, K. O’Sullivan ${ }^{2}$ and T. P. O'Connor ${ }^{1}$ \\ ${ }^{1}$ Department of Food and Nutritional Sciences and ${ }^{2}$ Department of Statistics, University College Cork, Cork, \\ Republic of Ireland
}

High dietary intakes of fat, particularly SFA, have been shown to be a risk factor for CVD in adulthood. The pathogenesis of atherosclerosis, a risk factor for CVD, has its origins in childhood. Furthermore, some of the modifiable risk factors for CVD have been identified in adolescents ${ }^{(1)}$. The consumption by adolescents of diets lower in beneficial MUFA and PUFA and higher in unfavourable SFA is increasing ${ }^{(2)}$. Trends in unhealthy dietary habits are very often maintained into adulthood. A longitudinal study of dietary, anthropometric and exercise variables was carried out annually from 2005 to 2007 inclusive in three secondary schools in County Cork, Ireland. A $3 \mathrm{~d}$ weighed dietary record was used to assess the food intake of 158 students aged 12-17 years in year 1 (ninety-seven girls, sixty-one boys). Dietary intakes for years 2 (aged 13-18 years) and 3 (aged 14-19 years) were also collected (not reported). Analysis of dietary intake data was conducted using WISP ${ }^{\circledR}$ (Tinuviel Software, Llanfechell, Anglesey, UK), which is based on McCance and Widdowson's The Composition of Foods, Sixth Edition ${ }^{(3)}$. Daily intakes (\% energy) of total fat, MUFA and PUFA are reported. The daily intakes of total fat $(\mathrm{g})$ were significantly higher for boys compared with girls in this study $(P<0.01)$. Boys also had significantly higher intakes $(\mathrm{g})$ of both SFA and MUFA $(P<0.05)$.

\begin{tabular}{|c|c|c|c|c|c|c|}
\hline & \multicolumn{2}{|c|}{$\begin{array}{l}\text { Total group } \\
(n \text { 158) }\end{array}$} & \multicolumn{2}{|c|}{$\begin{array}{l}\text { Girls } \\
(n \text { 97) }\end{array}$} & \multicolumn{2}{|c|}{$\begin{array}{l}\text { Boys } \\
(n \text { 61) }\end{array}$} \\
\hline & Mean & SD & Mean & SD & Mean & $\overline{S D}$ \\
\hline Total fat $(\mathrm{g} / \mathrm{d})$ & 77.7 & 30.4 & $72.6 * *$ & 27.4 & 85.7 & 33.4 \\
\hline SFA $(g / d)$ & 31.7 & 14.4 & $29.5^{*}$ & 12.3 & 35.2 & 16.8 \\
\hline MUFA (g/d) & 25.8 & 10.6 & $24.2 *$ & 9.3 & 28.5 & 12.1 \\
\hline PUFA (g/d) & 11.1 & 5.3 & 11 & 5.1 & 11.6 & 5.6 \\
\hline Total fat (\% daily energy) & 35.8 & 5.8 & 36.2 & 5.4 & 35.2 & 6.5 \\
\hline SFA ( \% daily energy) & 14.5 & 3.3 & 14.7 & 2.9 & 14.2 & 3.7 \\
\hline MUFA ( $\%$ daily energy) & 11.9 & 2.6 & 12.1 & 2.3 & 11.7 & 2.9 \\
\hline PUFA ( $\%$ daily energy) & 5.1 & 1.8 & 5.3 & 1.8 & 4.8 & 1.8 \\
\hline
\end{tabular}

Values were significantly different from those for boys: $* P<0.05, * * P<0.01$.

The mean contributions (\%) of total fat and SFA to total energy were higher than the current dietary guidelines of $<33$ and $<10$ respectively. The total group failed to meet the dietary guidelines for MUFA ( $\geq 12 \%$ total energy) and PUFA ( $\geq 6 \%$ total energy) ${ }^{(4)}$.The main food group contributors to mean daily total fat intakes were meat products $(25.5 \%)$, sugars and confectionery $(12.0 \%)$, milk and yoghurt $(11.5 \%)$ and butters, spreading fats and oils $(10.0 \%)$. These results indicate that the diet of Irish adolescents needs to be modified, with more emphasis being placed on the reduction of SFA intakes and increased consumption of MFA and PUFA.

This material is based on work supported by safefood, the Food Safety Promotion Board, under Grant no. 04-PG-20.

1. Monge R \& Beita O (2000) J Adolesc Health 27, 210-217.

2. Kyung LS, Novotny R, Daida YG, Vijayadeva V \& Gittelsohn J (2007) J Am Diet Assoc 107, 956-961.

3. Food Standards Agency (2002) McCance and Widdowson's The Composition of Foods, Sixth Edition. Cambridge: Royal Society of Chemistry.

4. Department of Health (1991) Dietary Reference Values for Food Energy and Nutrients for the United Kingdom. Report on Health and Social Subjects no. 41. London: H. M. Stationery Office. 